\title{
Adoção das IFRS no setor bancário brasileiro na percepção de especialistas, nos resultados e no nível de conservadorismo
}

\author{
Eliane Carolina Quaglio Arjonas - Faculdade FIPECAFI \\ (ORCID: 0000-0003-3818-8814) - eliane.quaglio@bancoalfa.com.br \\ Marta Cristina Pelucio Grecco - Faculdade FIPECAFI \\ (ORCID: 0000-0001-6994-4219) - marta.pelucio@praesum.com.br \\ Eric Barreto de Oliveira - Universidade de São Paulo, \\ Faculdade de Economia, Administração e Contabilidade (FEAUSP) \\ (ORCID: 0000-0002-8072-1224) - eric.barreto@m2msaber.com.br
}

RESUMO - o objetivo geral desse artigo é conhecer quais foram os efeitos da adoção parcial e compulsória das normas internacionais de contabilidade nos resultados dos bancos brasileiros, no nível de conservadorismo e na percepção dos gestores e profissionais da área contábil destas instituições, bem como auditores externos e analistas do mercado financeiro sobre essa forma de adoção. Com base nas demonstrações financeiras de 2010 a 2017 de sete bancos, para análise do conservadorismo foram utilizados índices de conservadorismo do Patrimônio Líquido e do Lucro Líquido adaptado de Gray (1988). Foi utilizado o teste de Wilcoxon para verificar as diferenças no ROE e ROA. Foi aplicada a técnica Delphi para captação da percepção de sete profissionais. Foram encontradas diferenças significativas entre o retorno do ativo apurado à luz do BACEN, em relação ao apurado à luz das IFRS. Ademais, os números divulgados segundo as regras do BACEN são mais conservadores, o que foi confirmado pelas entrevistas com os especialistas utilizando o método Delphi. Em relação aos efeitos práticos que a adoção das IFRS trouxe para o setor, foram citados pelos especialistas processos de controle interno, questões com o ambiente de TI, treinamento de pessoal, custo de observância e utilidade dessas demonstrações para cada tipo de instituição. Esse trabalho traz como contribuição prática e teórica junto aos profissionais e a academia, a compilação das implicações práticas do uso de dois conjuntos de normas (BACEN e IFRS) pelas instituições financeiras e as divergências entre elas no nível de conservadorismo e em suas medidas de desempenho.

Palavras-chave: BACEN, IFRS, ROE, ROA, Conservadorismo.

\section{IFRS adoption in the Brazilian banking sector on the perception of experts, on the results and on the level of conservatism}

\begin{abstract}
The aim of this article is to know the effects of the partial and compulsory adoption of international accounting standards on the results of Brazilian banks and on the perception of managers and professionals in the accounting area of these institutions, as well as external auditors and financial market analysts about this form of adoption. Based on the financial statements from 2010 to 2017 of seven banks, conservatism indexes of Net Equity and Net Profit adapted from Gray (1988) were used to analyze conservatism. The Wilcoxon test was used to verify differences in ROE and ROA. The Delphi technique was applied to capture the perception of seven professionals. Significant differences were found between the return on assets determined in the light of BACEN, in relation to that determined under IFRS. In addition, the figures released under the BACEN rules are more conservative, which was confirmed by interviews with experts using the Delphi method.
\end{abstract}


Regarding the practical effects that the adoption of IFRS has brought to the sector, internal control processes, issues with the IT environment, personnel training, compliance costs and the usefulness of these statements for each type of institution were mentioned by the specialists. This work brings as a practical and theoretical contribution to professionals and academia, the compilation of the practical implications of the use of two sets of standards (BACEN and IFRS) by financial institutions and the divergences between them in the level of conservatism and in their performance measures.

Keywords: BACEN, IFRS, ROE, ROA, Conservatism.

Data da Submissão: $01 / 10 / 2020$

Data de aceitação: 27/05/2021

Este artigo está licenciado sob forma de uma licença Creative Commons Atribuição-NãoComercial-SemDerivações 4.0 Internacional (CC BY-NC-ND 4.0) https://creativecommons.org/licenses/by-nc-nd/4.0/

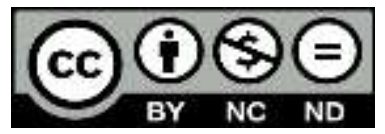

\section{Introdução}

O processo de convergência as normas internacionais é uma tendência mundial, iniciada pela Europa, que aplica esse conjunto de normas desde 2005. A padronização contempla a adoção de um novo padrão contábil que oferece mudanças cujo objetivo consiste em criar um conjunto único de demonstrações contábeis a nível mundial. Van Tendeloo e Vanstraelen (2005) mencionam, entre outas vantagens, que a adoção de um padrão único conduz a uma redução do risco para investidores e do custo do capital para as empresas.

Jeanjean e Stolowy (2008) argumentam que a adoção de um padrão único de demonstrações contábeis traz mais qualidade, aumenta a transparência e melhora a comparabilidade dos relatórios financeiros. Entretanto, os autores mencionam que há evidências de que os padrões contábeis desempenham apenas um papel limitado na determinação da qualidade dos relatórios observados. A aplicação de normas contábeis envolve considerável julgamento e uso de informações privadas e, como resultado, as International Financial Reporting Standards (IFRS) fornecem aos administradores uma discricionariedade substancial.

Por outro lado, independentemente destes aspectos, a internacionalização dos mercados, no que diz respeito ao desenvolvimento do mercado de capitais, ao crescimento dos investimentos diretos estrangeiros e à formação de blocos econômicos, traz consigo a necessidade de se ter um conjunto de padrões contábeis internacionais que possam viabilizar o processo de comparação de informações entre companhias de um mesmo grupo ou de grupos distintos (PADOVEZE; BENEDICTO; LEITE, 2012, p.3). Neste sentido, cabe argumentar que a convergência para um padrão contábil singular melhora a comparabilidade das companhias.

Em contraste, estudos como os de Ball, Robin e Wu (2003) apontam que em alguns países da Ásia Oriental, as demonstrações contábeis não são direcionadas apenas 
pelos padrões contábeis, os autores afirmam que estas dependem também dos fatores econômicos e políticos que incentivam os preparadores dessas informações.

Nesse sentido, Martins et al. (2013) reforçam que as mudanças mais relevantes decorrentes do processo de internacionalização dos padrões contábeis são: primazia da essência sobre a forma; normas orientadas por princípios e necessidade do julgamento por parte dos profissionais de contabilidade.

Segundo Macedo et al. (2010), o processo de convergência das normas contábeis brasileiras às IFRS pode ser caracterizado, dentre outros aspectos, como um processo de migração de um padrão de regulamentação contábil mais code law (enfatizam o direito formalista), para o padrão common law (enfatizam o direito consuetudinário), em que predomina a essência sobre a forma, cuja normas são baseadas mais em princípios do que em regras.

De acordo com Farias et al. (2014), a adoção de um novo padrão contábil implica mudanças na forma de evidenciação, mensuração, reconhecimento e divulgação dos fatos contábeis. As mudanças de padrão contábil também podem afetar atributos como qualidade e utilidade das informações divulgadas. Dentre esses atributos, destaca-se o conservadorismo, caracterizado pelo emprego de cautela, ao se evitar a superestimação de ativos e receitas e a subestimação de passivos e despesas. Neste estudo, os autores avaliaram os impactos que a adoção do IFRS trouxe na situação patrimonial, econômica e financeira dos bancos brasileiros.

No Brasil, a mudança de padrão contábil ocorreu a partir da Lei 11.638/07, que, conforme Antunes, Saiki e Pelucio-Grecco (2010), trouxe importantes conceitos do direito societário, adaptou conceitos legais utilizados em economias desenvolvidas e alinhou a normatização brasileira à legislação dos Estados Unidos e da Europa. Foram trazidas inovações tanto para as demonstrações contábeis quanto para as práticas contábeis, visto que as IFRS são muito mais baseadas em princípios do que em regras.

O Banco Central do Brasil (BACEN) foi um dos primeiros reguladores a se manifestar favoravelmente à convergência das normas contábeis em um único padrão. Isso fica evidenciado no comunicado 14.259 de 10/3/2006, em que o regulador menciona que algumas ações específicas seriam desenvolvidas com o objetivo de identificar a necessidade de convergência às normas internacionais de contabilidade, aplicáveis às instituições financeiras. Nesse comunicado, o BACEN menciona ainda que a partir do referido diagnóstico serão editados normativos objetivando a adoção de procedimentos para a elaboração e a publicação de demonstrações contábeis consolidadas em consonância com os pronunciamentos do Internacional Accounting Standard Board (IASB) a partir de 31 de dezembro de 2010.

Contudo, o BACEN, em 2010, com a emissão da Resolução 3.786, parece retroceder no processo de convergência, no qual obriga os bancos a apresentar suas demonstrações contábeis em dois padrões distintos, isto é, segundo os padrões contábeis definidos pelo BACEN, através das regras disponíveis no Plano Contábil das Instituições do Sistema Financeiro Nacional, o COSIF, e de acordo com as regras estabelecidas pelo IASB, disponíveis através das IFRS.

O BACEN optou por promover a convergência de uma forma mais lenta, sendo que até 2014 haviam sido recepcionados/adotados apenas sete pronunciamentos técnicos emitidos pelo Comitê de Pronunciamentos Contábeis (CPC), mantendo as normas contábeis divulgadas na Circular 1.273, enquanto os demais órgãos reguladores haviam

$$
133
$$

Arjonas, Eliane C. Q \& Pelucio-Grecco, Marta C. \& Oliveira, Eric B. Adoção das IFRS no setor bancário brasileiro na percepção de especialistas, nos resultados e no nível de conservadorismo 
aderido quase à totalidade dos pronunciamentos emitidos pelo $\mathrm{CPC}$, demonstrando um conservadorismo no reconhecimento de ativos, passivos, receitas e despesas por parte dos bancos brasileiros.

Considerando que os bancos brasileiros têm à disposição dois conjuntos de normas que devem ser seguidos, o padrão do BACEN e as IFRS, com algumas diferenças entre essas práticas contábeis e diante do grau de importância que o processo de convergência contábil teve ao redor do mundo e também no Brasil, o objetivo geral desse artigo é conhecer quais foram os efeitos da adoção parcial e compulsória das normas internacionais de contabilidade nos resultados dos bancos brasileiros, no nível de conservadorismo e na percepção dos gestores e profissionais da área contábil destas instituições, bem como auditores externos e analistas do mercado financeiro sobre essa forma de adoção.

Dessa forma, foram delineados os seguintes objetivos específicos:

- Analisar os impactos que a adoção das IFRS trouxe no desempenho dos bancos brasileiros, através da comparação dos resultados obtidos dos cálculos dos índices ROE (retorno sobre patrimônio líquido), ROA (retorno sobre os ativos) e IC (índice de conservadorismo) de Gray (1988), nos dois padrões contábeis (BACEN e IFRS);

- Analisar os impactos práticos da adoção das IFRS pelos bancos brasileiros, através de entrevista a gestores e profissionais da área contábil destas instituições, bem como auditores externos, com relação ao conservadorismo, às questões operacionais para implantação das novas regras, bem como a utilidade das demonstrações contábeis em IFRS.

De acordo com Dantas, Paulo e Medeiros (2013), estudos sobre conservadorismo na indústria bancária são recentes e escassos, o que justifica a importância desse artigo, que busca preencher uma lacuna de pesquisas sobre o efeito da adoção das IFRS no conservadorismo e na percepção dos profissionais sobre o conservadorismo nessa indústria. Ademais, conforme DE Freitas Daneberg e Decourt (2021), pesquisa sobre o impacto das IFRS em instituições financeiras muitas vezes não são abordadas, devido às suas particularidades, dessa forma, esse trabalho visa preencher essa lacuna.

Espera-se que esse trabalho contribua com a prática de profissionais de instituições financeiras no conhecimento da utilidade das demonstrações contábeis em IFRS e nas questões de implantação na percepção de especialistas. $\mathrm{O}$ conhecimento das divergências entre os dois modelos (BACEN e IFRS) pode apoiar normatizadores na busca de padrões contábeis mais simétricos, possibilitando a comparabilidade contábil. De acordo com Choi, Frost e Meek (2001), a vantagem da informação contábil mais comparável é a possibilidade de os usuários conseguirem analisá-las sem a necessidade de ser intimamente familiarizados com mais de um sistema contábil. Espera-se também que contribua com academia no conhecimento das divergências dos padrões contábeis do BACEN e do IFRS para as instituições financeiras e seus diferentes graus de conservadorismo.

\section{Referencias Conceituais}

O início da regulação da contabilidade remonta à década de 30 , sobretudo após a Grande Depressão de 1929, quando a regulação das instituições se intensificou. Nos Estados Unidos, os profissionais contábeis empreenderam uma grande quantidade de trabalho para estabelecer regras contábeis (TAVARES; ANJOS; PAULO, 2014). 


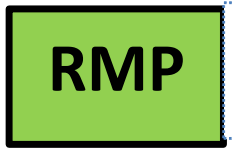

Ao longo dos anos, os Princípios Contábeis Geralmente Aceitos (GAAP Generally Accepted Accounting Principles) de cada país foram sendo influenciados pelo ambiente socioeconômico, resultando em uma grande diversidade de práticas contábeis. Isso ocasionou a falta de comparabilidade entre as demonstrações contábeis elaboradas em países de diferentes origens. Com a evolução da internacionalização dos negócios, ocorreu uma crescente indagação sobre como tornar comparáveis essas demonstrações contábeis (PELUCIO-GRECCO; GERON; FORMIGONI, 2009).

A promulgação da Lei 6.404/1976 foi o primeiro passo do Brasil no caminho da geração da informação aos usuários externos, em especial aos credores e aos investidores, e da própria harmonização contábil (MARTINS et al., 2014). Essa lei possui características baseadas no modelo norte-americano (MARTINS, 2012). Contudo, a contabilidade societária era influenciada por normas da Secretária da Receita Federal, agências reguladoras, fiscalizadoras e associações de profissionais. Como resultado, as demonstrações contábeis não acompanharam as demandas de seus usuários e não eram elaboradas de acordo com as disposições técnicas conhecidas mais adequadas, gerando uma perda na qualidade da informação contábil (MARTINS et al, 2013).

Assim, surgiu a necessidade de uma única normatização contábil no Brasil, suportada legalmente, mas não limitada por esse vínculo e caminhando rumo a uma única contabilidade mundial. Um dos principais resultados foi em 2005 através da emissão da Resolução 1.055/05, a criação do CPC, que tem como objetivo o estudo, o preparo e a emissão de pronunciamentos técnicos sobre procedimentos de contabilidade.

O marco legal no Brasil referente ao início do processo de adoção do padrão internacional de contabilidade aconteceu em 2007, com a promulgação da Lei 11.638/07, que propôs alterações nos princípios contábeis. A estratégia adotada foi a adoção gradual, sendo que para os exercícios sociais de 2008 foi exigida a adoção de 14 normas e apenas a partir do exercício social de 2010 se determinou a adoção completa. Algumas companhias abertas optaram por adotar completamente as IFRS antecipadamente. Esse movimento foi denominado adoção voluntária. Dessa forma, a partir do exercício de 2008 algumas demonstrações contábeis publicadas já contemplavam o padrão de normas internacionais (SILVA, 2013).

A promulgação da Lei 11.638/07 trouxe ao cenário nacional uma nova filosofia contábil, a primazia da essência sobre a forma. Essa estrutura conceitual defende um modelo contábil regido por princípios e julgamentos e não somente por regras, em que a informação contábil deverá representar adequadamente os eventos ocorridos (GERON, 2008). O movimento de adoção das normas internacionais de contabilidade no Brasil pode ser explicado por diversos aspectos, destacando-se a redução das taxas inflacionárias e a expansão do mercado de capitais, o que ocasionou o aumento da importância das informações contábeis no processo de decisão de investimentos (ANTUNES et al., 2012).

No entanto, em relação às instituições financeiras e às demais instituições autorizadas a funcionar pelo BACEN, compreendendo bancos múltiplos, bancos de investimentos, bancos comerciais, bancos de desenvolvimento, cooperativas de crédito, sociedades de arrendamento mercantil e sociedades de crédito, cabe ao órgão regulador emitir as normas pertinentes às instituições. Elas têm à disposição o COSIF, que foi criado com a edição da Circular no. 1.273, em 29 de dezembro de 1987, com o objetivo de unificar os diversos planos contábeis existentes na época e uniformizar os procedimentos de registro e elaboração de demonstrações contábeis. 
Dessa forma, as instituições financeiras utilizam um arcabouço contábil próprio em relação tanto às normas emanadas do BACEN quanto ao COSIF. Essas normas, porém, pouco mudaram para se adequar ao padrão internacional de contabilidade.

Essa separação entre instituições financeiras e não financeiras está estabelecida na Lei 4.595/64, que determina entre outros assuntos, a competência do CMN para expedir normas gerais de contabilidade e estatística a serem observadas pelas instituições financeiras e pela Lei 6.385/76, que reforça essa competência. Portanto, cumprindo suas atribuições, o BACEN promulgou o Comunicado 14.259/06, que divulga procedimentos para a convergência das normas de contabilidade e auditoria aplicáveis às instituições financeiras com as normas internacionais promulgadas pelo IASB.

Entre outras atribuições, o comunicado estabeleceu a data-limite de 31 de dezembro de 2010 para a elaboração e a publicação de demonstrações contábeis consolidadas conforme o padrão das IFRS, ou seja, alinhando as datas que vierem a ser estabelecidas pelo CPC e CVM. Entretanto, o BACEN pensa no equilíbrio entre transparência e estabilidade do sistema, de modo que os impactos sejam meticulosamente analisados anteriormente à introdução de uma nova norma (GIROTTO, 2013).

Nesse cenário, o BACEN edita a Resolução CMN 3.786/09, na qual altera um pouco o contexto e reitera a obrigação das instituições financeiras e das demais instituições autorizadas a funcionar pelo Banco Central do Brasil, constituídas sob a forma de companhia aberta ou que sejam obrigadas a constituir comitê de auditoria nos termos da regulamentação em vigor, a elaborar e divulgar anualmente demonstrações contábeis consolidadas adotando o padrão contábil internacional, de acordo com os pronunciamentos emitidos pelo IASB quanto ao prazo para a primeira divulgação dessas demonstrações contábeis, surgindo a partir desse momento dois conjuntos distintos de demonstrações contábeis.

No caminho do processo de convergência, foi emitido pelo CPC um total de 46 pronunciamentos técnicos e um pronunciamento conceitual. Entretanto, o BACEN homologou apenas oito desses pronunciamentos, demonstrando que o processo de convergência não foi integralmente adotado, nos quais o regulador demonstra que as mudanças acontecerão de maneira mais gradual e lenta.

Os pronunciamentos adotados pelo BACEN foram: CPC 00 (R1) Estrutura conceitual para elaboração e divulgação de relatório contábil-financeiro; CPC 01 (R1) Redução de valor recuperável de ativos; CPC 03 (R2) Demonstrações de fluxo de caixa; CPC 05 (R1) Divulgação de partes relacionadas; CPC 10 (R1) Pagamento baseado em ações; CPC 23 Políticas contábeis, mudança de estimativa e retificação de erro; CPC 24 Evento subsequente; e CPC 25 Provisões, passivos contingentes e ativos contingentes.

\subsection{Principais diferenças entre as normas do BACEN e das IFRS/CPC}

As tabelas 1 a 4 representam de forma não exaustiva as principais diferenças entre as normas vigentes nas instituições financeiras que seguem as normas do BACEN e as normas descritas nas IFRS/CPC. Essas diferenças foram observadas nas notas explicativas de reconciliação entre o resultado divulgado nas IFRS e o resultado divulgado de acordo com as normas do BACEN, publicado nas demonstrações contábeis de alguns bancos. 
Tabela 1 - Divergência entre BACEN x Framework e IFRS 3.

\section{IFRS / CPC}

Norma

\section{Definição}

Framework/ Dispõe sobre as demonstrações contábeis O BACEN prevê a segregação no $\mathrm{CPC} 00$

\section{elaboradas e divulgadas pelas entidades e a} base para a apresentação dessas demonstrações balanço patrimonial dos ativos não correntes em "ativo realizável a longo prazo" e "ativo permanente"

IFRS 3/ O adquirente deve mensurar os ativos Para o BACEN, os ativos e passivos

CPC 15/ adquiridos e os passivos assumidos pelos objetos de uma combinação de negócio

Combinação de valores justos da data da aquisição. Em são mantidos pelo valor contábil

negócios cada combinação, o adquirente deve mensurar, na aquisição, os componentes da participação de não controladores na adquirida que representem nessa data de fato instrumentos patrimoniais e confiram a seus detentores uma participação proporcional nos ativos líquidos da adquirida em caso de sua liquidação, por um dos seguintes critérios:

(a) pelo valor justo, ou (b) pela participação proporcional conferida pelos instrumentos patrimoniais nos montantes reconhecidos dos ativos líquidos identificáveis

IFRS 3/ De acordo com o CPC 15, quando a Nas operações de incorporação, de CPC 15/ controladora adquirir mais ações ou outros acordo com o BACEN, a sociedade Combinação de instrumentos patrimoniais de uma entidade incorporada detém participação no negócios que já controla deve considerar esse valor como redução de seu patrimônio líquido

capital da incorporadora, o ágio ou deságio existente na incorporada, quando não baixado no momento da incorporação, deve ser contabilizado no ativo como ágio ou deságio na aquisição do investimento, que é a diferença entre $o$ custo de aquisição e o valor patrimonial das ações

IFRS 16/ A IFRS 16 elimina o arrendamento No Brasil, as operações de

CPC 06/

Arrendamento mercantil operacional, passando a existir um único modelo de contabilização pelo arrendatário, em que todos os arrendamentos serão reconhecidos no balanço patrimonial do arrendatário, sendo registrado um passivo para pagamentos futuros e um ativo intangível para o direito de uso.

As entidades, a partir de 1 de janeiro de 2019, deverão avaliar se tanto os contratos novos como os antigos são ou contêm um arrendamento. Para os contratos em que forem identificados um arrendamento, a entidade deverá reconhecer o ativo de direito de uso e o passivo de arrendamento arrendamento mercantil no âmbito do SFN são regulamentadas pela Resolução 2.309/96, alterada pela Resolução 4.696, que estabelece que o arrendador deve registrar as operações de arrendamento mercantil financeiro no ativo, deduzidas das rendas a apropriar. As rendas do devem ser apropriadas mensalmente durante a fluência do contrato.

As financeiras avaliarão pelas novas regras das IFRS 16, para fins de divulgação nas IFRS, quais contratos se encaixam como arrendamento mercantil e contabilizá-los seguindo essas regras, o que gerará mais uma diferença de padrão contábil

Fonte: Elaborado pelos autores. 
Tabela 2 - Divergência entre BACEN x IFRS 9 - Classificação de Ativos e Passivos Financeiros.

\begin{tabular}{|c|c|}
\hline \multicolumn{2}{|r|}{ IFRS / CPC } \\
\hline Norma & Definição \\
\hline IFRS 9/ & Preveem que os ativos financeiros \\
\hline CPC 48/ & sejam classificados em: custo \\
\hline Financeiros & amortizado; valor justo por meio do \\
\hline Classificação & $\begin{array}{l}\text { resultado; e valor justo por meio do } \\
\text { resultado abrangente. }\end{array}$ \\
\hline
\end{tabular}

Custo amortizado - $\mathrm{O}$ ativo será assim classificado se:

\section{Divergência BACEN X IFRS}

(a) o ativo financeiro for mantido dentro de modelo de negócios cujo objetivo seja manter ativos financeiros com o fim de receber fluxos de caixa contratuais;

(b) os termos contratuais do ativo financeiro derem origem, em datas especificadas, a fluxos de caixa que constituam,

exclusivamente, pagamentos de principal e juros sobre o valor do principal em aberto. Valor justo por meio do resultado abrangente - $\mathrm{O}$ ativo será assim classificado se as seguintes condições forem atendidas: (a) o ativo financeiro for mantido destinação específica ou vínculo à comprovação da dentro de modelo de negócios cujo aplicação dos recursos;

objetivo seja atingido tanto pelo b) títulos descontados - operações de desconto de recebimento de fluxos de caixa títulos;

contratuais quanto pela venda de c) financiamentos - são as operações realizadas ativos financeiros;

(b) os termos contratuais do ativo financeiro derem origem, em datas especificadas, a fluxos de caixa que constituam

exclusivamente pagamentos de principal e juros sobre o valor do principal em aberto. Valor justo por meio do resultado -O ativo é assim se não enquadrado nas condições anteriores.

A entidade pode, no reconhecimento inicial, designar de modo irrevogável o ativo financeiro como mensurado ao valor justo por meio do resultado se, ao fazê-lo, puder eliminar ou reduzir uma inconsistência de mensuração ou de reconhecimento (algumas vezes referida como "descasamento pel contábil"), que, de outro modo, pode resultar da mensuração de ativos ou passivos ou do reconhecimento de ganhos e perdas nesses ativos e passivos em bases diferentes com destinação específica, vinculadas à comprovação da aplicação dos recursos.

Desde 2017, o BACEN classifica os instrumentos financeiros em: custo amortizado: os ativos que atendam às condições de fluxos de caixa futuros, constituindo exclusivamente o pagamento de principal e de juros, e, de acordo com o modelo de principal e juros; valor justo no patrimônio líquido: os ativos que atendam às condições de fluxos de caixa futuros, constituindo exclusivamente o pagamento de principal e juros, e, de acordo com o modelo de negócio cujo objetivo seja o recebimento de principal e de juros quanto pela venda do ativo financeiro com transferência substancial de riscos e benefícios; valor justo no resultado: operações geridas dentro do modelo de negócio cujo objetivo seja gerar retorno somente pela venda do ativo financeiro e operações que não constituam exclusivamente para pagamento de principal e de juros. Cabe salientar que tal edital de consulta até $02 / 2019$, não havia sido transformado em resolução e, dessa forma, considera como vigentes as regras da Resolução 3.068/01 negócio cujo objetivo seja o recebimento de

Fonte: Elaborado pelos autores. 
Tabela 3 - Divergência entre BACEN x IFRS 9 - Método de juros efetivo e valor justo dos instrumentos financeiros derivativos.

IFRS / CPC

\section{Norma}

IFRS 9 / Método de juros efetivos: Ao aplicar o

CPC 48/ método de juros efetivos, a entidade

Instrumentos identifica taxas que são parte integrante

financeiros/ da taxa de juros efetiva do instrumento

Método de financeiro, que inclui: a) taxas de

juros efetivos originação recebidas ou pagas pela entidade relacionadas à criação ou à aquisição do ativo/passivo financeiro; e b) taxa de compromisso que deve ser considerada como remuneração pelo envolvimento contínuo com a aquisição do instrumento financeiro. Ao aplicar o método de juros efetivos, a entidade, de modo geral, deve amortizar quaisquer taxas, pontos pagos ou recebidos, custos de transação e outros prêmios ou descontos incluídos no cálculo da taxa de juros efetiva ao longo da vida esperada do instrumento financeiro

IFRS 9/ A entidade deve classificar os
CPC 48/ derivativos a valor justo por meio do

Valor justo de resultado.

instrumentos No reconhecimento inicial, uma entidade financeiros poderá designar de modo irrevogável um derivativos ativo ou passivo para a categoria ao valor justo por meio do resultado, se essa opção eliminar ou reduzir significativamente uma inconsistência de mensuração ou reconhecimento inicial

\section{Divergência BACEN x IFRS}

As normas de contabilidade societária aplicadas às instituições financeiras autorizadas a funcionar pelo Banco Central do Brasil preveem que certos encargos relacionados a determinados ativos financeiros sejam reconhecidos no resultado no momento da origem da operação; outros encargos como comissões pagas a lojistas e revendedores são registrados em rubrica de "outros ativos despesas antecipadas" e reconhecidos no resultado de forma linear pelo prazo das respectivas operações (Fonte: Circular 3.693 de 20/12/2013, circular 3.738 de 11/12/2014)

A Circular 3.150 de 11 de setembro de 2002, que altera o art. $2^{\circ}$ da Circular 3.082, de 30 de janeiro de 2002, menciona que as operações com instrumentos financeiros derivativos devem ser avaliadas a valor de mercado, no mínimo, por ocasião dos balancetes mensais, computando a valorização ou a desvalorização em contrapartida à adequada conta de receita ou de despesa no resultado do período. Porém, o parágrafo $2^{\circ}$ do art. $1^{\circ}$ informa que, quando o instrumento financeiro derivativo for contratado em negociação associada, a operação de captação ou aplicação de recursos e a valorização ou desvalorização decorrente de ajuste a valor de mercado poderão ser desconsideradas, desde que atendidas as seguintes exigências: i) não seja permitida a negociação ou liquidação em separado da operação a ele associada;

ii) nas hipóteses de liquidação antecipada da operação associada, a mesma ocorra pelo valor contratado;

iii) o valor seja contratado pelo mesmo prazo e com a mesma contraparte da operação associada

Fonte: Elaborado pelos autores. 
Tabela 4 - Divergência entre BACEN x IFRS 9 - Redução ao valor recuperável.

\begin{tabular}{|c|c|c|}
\hline \multicolumn{2}{|r|}{ IFRS / CPC } & \multirow{2}{*}{ Divergência BACEN x IFRS } \\
\hline Norma & Definição & \\
\hline $\begin{array}{l}\text { IFRS 9/CPC } \\
48 \\
\text { Redução ao } \\
\text { valor } \\
\text { recuperável }\end{array}$ & $\begin{array}{l}\text { O modelo de redução ao valor recuperável de } \\
\text { ativos financeiros das IFRS 9/CPC } 48 \text { é } \\
\text { baseado no conceito de perda esperada. Em } \\
\text { cada data de relatório, a entidade deve avaliar } \\
\text { se o risco de crédito de instrumento financeiro } \\
\text { aumentou desde o reconhecimento inicial. As } \\
\text { IFRS9/CPC } 48 \text { preveem um modelo de três } \\
\text { estágios para o reconhecimento da redução do } \\
\text { valor recuperável } \\
\text { Estágio I: Classificam-se nesse estágio os } \\
\text { ativos financeiros que não sofreram aumento } \\
\text { significativo do risco de crédito desde o } \\
\text { reconhecimento inicial. Constituição das } \\
\text { PECLD (Perdas Estimadas em Crédito de } \\
\text { Liquidação Duvidosa) com base nas perdas } \\
\text { de crédito esperadas para o próximo ano } \\
\text { Estágio II: O risco de crédito relacionado ao } \\
\text { ativo financeiro aumentou significativamente } \\
\text { desde o reconhecimento inicial, porém não há } \\
\text { evidências objetivas do evento da perda. } \\
\text { Constituição das PECLD nas perdas de } \\
\text { crédito esperadas pela vida toda do ativo. } \\
\text { Estágio III: Ativos financeiros com evidência } \\
\text { objetiva de perda. Constituição das PECLD } \\
\text { com base nas perdas de crédito esperadas para } \\
\text { a vida toda do ativo }\end{array}$ & $\begin{array}{l}\text { O modelo de redução do valor recuperável } \\
\text { de ativos segue as regras da Resolução } \\
2.682 \text {, que determina a classificação dos } \\
\text { créditos concedidos de acordo com o risco } \\
\text { das operações e o tempo de atraso, } \\
\text { considerando o histórico do cliente e sua } \\
\text { capacidade como tomador de empréstimo e } \\
\text { sua capacidade de pagamento futuro. } \\
\text { A provisão vai de } 0,5 \% \text {, nível A, que ainda } \\
\text { não apresenta atraso, até } 100 \% \text { no nível H, } \\
\text { com atraso entre } 151 \text { e } 180 \text { dias. } \\
\text { Cabe mencionar que o BACEN divulga } \\
\text { propostas de atos normativos, dispondo } \\
\text { sobre critérios contábeis para constituição } \\
\text { de provisão para perda esperada, sob risco } \\
\text { de crédito em três estágios: } \\
\text { Estágio I: Instrumentos financeiros que de } \\
\text { início não sejam caracterizados como ativo } \\
\text { financeiro com problemas de crédito. } \\
\text { Estágio II: Instrumentos financeiros cujo } \\
\text { risco aumentado. Considera-se aumento do } \\
\text { risco o atraso superior a } 30 \text { dias de elevação, } \\
\text { quando aumenta a probabilidade de o } \\
\text { instrumento financeiro ser dito problema. } \\
\text { Estágio III: Instrumentos financeiros com } \\
\text { problemas de recuperação de crédito em } \\
\text { observância às regras da Resolucão } 2682\end{array}$ \\
\hline $\begin{array}{l}\text { IAS 38/CPC } \\
04 \quad(\mathrm{R} 1) \quad- \\
\text { Ativo } \\
\text { intangível }\end{array}$ & $\begin{array}{l}\text { O ágio derivado da expectativa de } \\
\text { rentabilidade futura (goodwill) reconhecido } \\
\text { em uma combinação de negócios é um ativo } \\
\text { que representa benefícios econômicos futuros } \\
\text { gerados por outros ativos adquiridos em uma } \\
\text { combinação de negócios que não são } \\
\text { identificados individualmente e reconhecidos } \\
\text { separadamente. } \\
\text { Esse ágio derivado da expectativa de } \\
\text { rentabilidade futura é considerado um ativo } \\
\text { com vida útil indefinida e não deve ser } \\
\text { amortizado, mas testado para fins de } \\
\text { determinação de seu valor recuperável ao } \\
\text { menos uma vez por ano, e sempre que houver } \\
\text { indicação de que o ágio possa sofrer redução } \\
\text { no valor recuperável }\end{array}$ & $\begin{array}{l}\mathrm{O} \text { ágio é amortizado sistematicamente } \\
\text { durante um período de até dez anos e o ágio } \\
\text { registrado está sujeito ao teste de } \\
\text { recuperabilidade pelo menos uma vez por } \\
\text { ano, ou em menor período no caso de } \\
\text { alguma indicação de redução do valor } \\
\text { recuperável do ativo }\end{array}$ \\
\hline
\end{tabular}

Fonte: Elaborado pelos autores.

\subsection{Conservadorismo contábil}

O conservadorismo pode ser entendido como sendo um comportamento cauteloso em relação aos eventos futuros, os quais são incertos (GRAY, 1988). No mesmo sentido, Basu (1997) interpreta o conservadorismo como algo que captura a tendência dos contadores de exigir um maior grau de verificação para reconhecer boas notícias do que 
más notícias nas demonstrações contábeis. Neste sentido, os lucros refletem as más notícias mais rapidamente do que boas notícias.

Desse modo, o conservadorismo é visto como as exigências de um alto padrão de investigação para reconhecer as boas notícias como lucros, o que não ocorre com as más notícias como perdas. Como consequência, o lucro contábil reflete as más notícias em uma base mais oportuna que as boas notícias, estabelecendo um padrão de reconhecimento assimétrico entre perdas e ganhos na contabilidade (Basu, 1997).

Paulo, Antunes e Formigoni (2008) mencionam que umas das principais características da qualidade das informações contábeis, porém de natureza subjetiva é o conservadorismo. $\mathrm{O}$ conservadorismo sofre algumas críticas na sua aplicação por alguns práticos e teóricos da contabilidade, como por exemplo, Santos et al (2011), que citam que o grau de conservadorismo nas demonstrações contábeis é conveniente, e que em muitas situações, a observância do conservadorismo contradiz a aplicação de outros princípios contábeis. Menciona ainda, que o conservadorismo provoca viés sistemático nas informações contábeis, tornando os procedimentos contábeis adotados pela firma inconsistentes na mediação do lucro, pois, quando ocorre a subavaliação de um ativo, no futuro haverá uma avaliação exagerada do lucro quando o ativo for utilizado ou vendido.

Santos et al. (2011) investigaram se a promulgação da Lei no. 11.638/07 alterou o grau de conservadorismo contábil condicional de empresas brasileiras listadas na Bovespa e BM\&F BOVESPA. No estudo os autores ajustaram o modelo de Basu para medir o efeito da Lei no. 11.638/07 no conservadorismo condicional. Na amostra analisada, não foi possível inferir se as novas regras tiveram algum efeito sobre o grau de reconhecimento assimétrico de perdas e ganhos.

Watts (2003) define conservadorismo como a verificabilidade diferencial necessária para o reconhecimento de lucros versus perdas. Em seu estudo liga o conservadorismo com as relações contratuais, tributação e regulamentação contábil. No caso da tributação o efeito do conservadorismo está na relação entre o lucro e o desembolso tributário, onde as empresas por meio do diferimento da receita e antecipação da despesa reduzem o valor o valor do tributo.

Gray (1988) em seu estudo sobre como a contabilidade segue padrões diferentes em diferentes partes do mundo, definiu quatro accounting values, que expressam as origens socioculturais das diferenças entre os países: profissionalismo x controle estatutário; uniformidade x flexibilidade; conservadorismo x otimismo; e segredo x transparência.

Como metodologia quantitativa para expressar o impacto dessas influências culturais e institucionais no resultado reportado pelas empresas, Gray (1988) propôs o Índice de Conservadorismo, que mais tarde foi renomeado por Weetman et al. (1998) para Índice de Comparabilidade Total (IC, referente a todo resultado) ou Índice de Comparabilidade Parcial (ICP, referente a cada ajuste específico). O resultado da aplicação da fórmula do IC ou ICP revela que índices maiores que 1 denotam conservadorismo e índices menores que 1 indicam otimismo.

Conforme Brito, Lopes e Coelho (2012) gestores de bancos estatais brasileiros reportam demonstrações financeiras mais conservadoras, provavelmente para reduzir exposição ao risco de litígio com órgãos de controle governamental. Já em Portugal, não foi encontrado esse conservadorismo em bancos, conforme evidenciaram De Lima, Da Fonseca e Brito (2009). 
Ademais, Queiroz, Rodrigues, Da Silva Macedo e Szuster (2020) encontraram evidências de que os bancos com valores mais baixos de instrumentos financeiros são conservadores, diferentemente daqueles com valores mais altos de instrumentos financeiros.

Dos diversos estudos desenvolvidos sobre conservadorismo, são raros os estudos que analisam o assunto no setor de empresas financeiras. Conforme Pelucio-Grecco, Geron e Macias (2019) e Santos e Calixto (2010), aplicando a teoria da influência cultural e o índice de conservadorismo de Gray (1988), a adoção das IFRS resultou em diminuição do conservadorismo no Brasil de entidades não financeiras, no entanto, na Colômbia houve acréscimo do conservadorismo. Dessa forma, baseado como o comportamento de cada setor pode influenciar o conservadorismo dos números contábeis, tornou-se a oportunidade de analisar se há diferenças significativas nos números contábeis dos bancos brasileiros considerando os dados divulgados nas demonstrações contábeis segundo os padrões contábeis do BACEN e comparando com os dados divulgados de acordo com as IFRS, utilizando o Índice de Conservadorismo.

\section{Procedimento Metodológico}

Visando alcançar o objetivo proposto o presente trabalho adotou-se a estratégia de pesquisa mista que utiliza dados e análises quantitativas e qualitativas.

Para análise quantitativa foram coletados dados secundários de informações nas demonstrações financeiras divulgadas pelos bancos para atendimento do primeiro objetivo específico de analisar os impactos que a adoção das IFRS trouxe no desempenho dos bancos brasileiros, através da comparação dos resultados obtidos dos cálculos dos índices ROE (retorno sobre patrimônio líquido), ROA (retorno sobre os ativos) e IC (índice de conservadorismo) de Gray (1988), nos dois padrões contábeis (BACEN e IFRS).

A coleta de dados secundários ocorreu através das demonstrações contábeis disponibilizadas no site da CVM ou no site das próprias empresas. O período analisado compreendeu as demonstrações financeiras consolidadas dos exercícios findos de 2010 a 2017. Considerando que fez parte da análise a comparação dos números divulgados tanto nos padrões do BACEN quanto na base das IFRS, foram coletadas as demonstrações contábeis elaboradas de acordo com os dois padrões contábeis.

A amostra desse estudo se baseou na relação dos bancos com registro concedido na CVM, sendo excluídos: os que possuem patrimônio líquido inferior a $\mathrm{R} \$ 1$ bilhão na database 30 de junho de 2018; os que não possuem ações negociadas em bolsa; os que deixaram de apresentar suas demonstrações contábeis nos dois padrões contábeis com registro concedido pela CVM após 2010; e aqueles pertencente a algum conglomerado que é base da amostra, com algum problema financeiro ou com o órgão regulador. Dessa forma, a amostra final foi composta por sete bancos: Banco ABC Brasil (ABC), Banco Alfa de Investimento (Alfa), Banco Daycoval (Daycoval), Banco do Brasil (BB), Banco do Estado do Rio Grande do Sul

Os indicadores estudados foram apurados a partir dos dados extraídos das demonstrações financeiras à luz da BACEN e à luz das IFRS, em linha com Pessanha, Calegario, Safadi e De Azara (2012) e Duan e Niu (2020), conforme fórmulas a seguir: 
$\mathrm{ROE}=\mathrm{LL} / \mathrm{PL}$ (em que LL representa lucro líquido do período e PL saldo final do patrimônio líquido do período.)

\section{$\mathrm{ROA}=\mathrm{LL} / \mathrm{AT}$ (em que LL representa lucro líquido do período e AT saldo final do ativo do período.)}

Para análise do conservadorismo relativo entre os dois modelos contábeis (BACEN e IFRS), utilizou-se o modelo adaptado do Índice de Conservadorismo de Gray (1988) para o patrimônio líquido e para o lucro líquido.

ICPL BRGAAP $=1-[($ PL BRGAAP - PL IFRS $)]$ / [PLBRGAAP $]$

(onde ICPL é o índice de conservadorismo do Patrimônio Líquido, PL BRGAAP representa o PL em BRGAAP, PL IFRS representa o PL em IFRS e [PLBRGAAP] representa o valor absoluto do PL em BRGAAP.)

- Se ICPL maior que 1, então o patrimônio líquido em BRGAAP é mais conservador que o IFRS;

- Se ICPL menor que 1, então o patrimônio líquido em BRGAAP é menos conservador que o IFRS.

\section{ICLL BRGAAP $=1-$ [(LL BRGAAP - LL IFRS $)] /$ [LLBRGAAP]}

(Onde ICLL é o índice de conservadorismo do Lucro Líquido,

LL BRGAAP representa o LL em BRGAAP,

LL IFRS representa o LL em IFRS e

[LLBRGAAP] representa o valor absoluto do LL em BRGAAP.)

- Se ICPL maior que 1, então o lucro líquido em BRGAAP é mais conservador que o IFRS;

- Se ICPL menor que 1, então o lucro líquido em BRGAAP é menos conservador que o IFRS.

Para verificar se existem diferenças estatísticas significativas entre o ROE e ROA apurados pelos dois modelos contábeis (BACEN e IFRS) será aplicado o teste não paramétrico de Wilcoxon. Para verificar a normalidade dos dados da amostra será aplicado o teste de Kolmogorov-Smirnov. Ambos testes serão efetuados no software SPSS e considerando o nível de significância de 5\%.

Para a análise qualitativa foram coletados dados primários, para atender ao segundo objetivo específico de analisar os impactos práticos da adoção das IFRS pelos bancos brasileiros, através de entrevista a gestores e profissionais da área contábil destas instituições, bem como auditores externos, com relação ao conservadorismo, às questões operacionais para implantação das novas regras, bem como a utilidade das demonstrações contábeis em IFRS.

Para a obtenção de dados primários, foram entrevistados: 1 diretor da área de controladoria de um banco; 1 sócio de auditoria externa; 1 gerente sênior de auditoria externa; 1 gerente contábil de instituição financeira; 1 contador responsável por preparar as demonstrações financeiras; 1 profissional da área de políticas contábeis de uma 
instituição financeira; 1 profissional de consultoria, com experiência também na área de políticas contábeis de uma instituição financeira. As entrevistas foram realizadas entre outubro e dezembro de 2018.

As entrevistas foram elaboradas utilizando o método Delphi, que consiste em obter o consenso de especialistas sobre o que está sendo investigado (VERGARA, 2015). O método Delphi é a aplicação sucessiva de questionários a um grupo de especialista ao longo de algumas rodadas, com o objetivo de se chegar a um consenso do grupo sobre a matéria estudada (GRECCO; PELUCIO-GRECCO; ANTUNES, 2016). As entrevistas com esses profissionais continham as seguintes questões abertas sobre cargo, experiência, conservadorismo, efeitos práticos vivenciados no processo de implantação das IFRS na instituição financeira que atua e utilidade da demonstração financeira preparada e divulgada conforme os padrões internacionais para sua instituição financeira.

A primeira ação após a realização das entrevistas foi transcrevê-las, encaminhá-las aos profissionais entrevistados para que pudessem validar a transcrição e adicionar novos comentários, se necessário. e efetuar a análise de conteúdo. A análise de conteúdo é um conjunto de técnicas de análise das comunicações, visando, por procedimentos sistemáticos e objetivos de descrição do conteúdo das mensagens, obter indicadores quantitativos ou não, que permitam a inferência de conhecimentos relativos as condições de produção/recepção variáveis inferidas das mensagens (BARDIN, 1977 apud TRIVIÑOS, 1987, p. 160).

Neste sentido, a análise de conteúdo é uma técnica de análise das comunicações, que irá analisar o que foi dito nas entrevistas ou observado pelo pesquisador. Na análise do material, busca-se classificá-los em temas ou categorias que auxiliam na compreensão do que está por trás dos discursos. Neste caso, o material coletado foi classificado em perguntas e respostas.

\section{APRESENTAÇÃO E ANÁLISE DOS RESULTADOS}

\subsection{Análise quantitativa do ROE, ROA e Índice de Conservadorismo}

O ROE e o ROA das empresas da amostra nos anos estudados foram apurados conforme descrito nos procedimentos metodológicos e a estatística descritiva está demostrada na Tabela 5.

Tabela 5 - Estatística descritiva ROE e ROA.

\begin{tabular}{lrrrrr}
\hline & Qtd de observações & \multicolumn{1}{c}{ Média } & Desvio Padrão & Mínimo & Máximo \\
ROE_BACEN & 56 & $13,8793 \%$ & $5,81024 \%$ & $3,35 \%$ & $25,07 \%$ \\
ROA_BACEN & 56 & $1,3334 \%$ &, $61672 \%$ &, $37 \%$ & $3,07 \%$ \\
ROE_IFRS & 56 & $13,4871 \%$ & $4,76357 \%$ & $3,49 \%$ & $22,93 \%$ \\
ROA_IFRS & 56 & $1,5107 \%$ &, $59589 \%$ &, $39 \%$ & $2,97 \%$ \\
\hline
\end{tabular}

Fonte: Elaborado pelos autores a partir dos dados da pesquisa.

A estatística do teste de Kolmogorov-Smirnov com nível de significância de 5\% apontou que tanto o ROE quanto o ROA dos dois modelos estudados apresentam distribuição normal.

Ao aplicar o teste não paramétrico de Wilcoxon, constatou-se que a diferenças do ROA apurado pelos dois modelos contábeis pelas empresas e anos da amostra são 
estatisticamente significativas, com nível de significância de $1 \%$, o que não se comprou para o ROE.

Dessa forma, pode-se afirmar que existem diferenças significativas para análise de desempenho em relação aos ativos quando se utiliza informações contábeis do BACEN e do IFRS. Para verificar qual dos conjuntos de informações é mais conservador, utilizou-se o índice de conservadorismo.

Para o cálculo do índice de conservadorismo, tabularam-se em planilha Excel os saldos do patrimônio líquido e do lucro líquido, partindo das demonstrações financeiras divulgadas pelos sete bancos selecionados na amostra nos anos estuados. Na Tabela 6 estão representados os índices apurados.

Tabela 8 - Índice de Conservadorismo.

\begin{tabular}{ccccccccc}
\hline \multicolumn{7}{c}{ Painel A - Índice de Conservadorismo para o Patrimônio Líquido (ICPL) } \\
\hline Instituição financeira & $\mathbf{2 0 1 0}$ & $\mathbf{2 0 1 1}$ & $\mathbf{2 0 1 2}$ & $\mathbf{2 0 1 3}$ & $\mathbf{2 0 1 4}$ & $\mathbf{2 0 1 5}$ & $\mathbf{2 0 1 6}$ & $\mathbf{2 0 1 7}$ \\
\hline Banco ABC S.A. & 1 & 1 & 1,03 & 1,04 & 1,04 & 1,05 & 1,03 & 1,04 \\
Banco Alfa de Investimento & 1 & 1 & 1,02 & 1,01 & 1,01 & 1,01 & 1,03 & 1,01 \\
Banco Daycoval S.A. & 1 & 1,43 & 1,54 & 1,3 & 1,33 & 1,01 & 1,02 & 1,03 \\
Banco do Brasil S.A. & 1,08 & 1,07 & 1,06 & 1,06 & 1,06 & 1,06 & 1,03 & 1,03 \\
Banco do Estado do Rio Grande do Sul S.A. & 1,04 & 1,04 & 1,04 & 1,04 & 1,02 & 1,04 & 1,04 & 1,05 \\
Banco Santander Brasil S.A. & 1,13 & 1,19 & 1,25 & 1,3 & 1,37 & 1,46 & 1,47 & 1,46 \\
Banco Itaú Unibanco Holding S.A. & 1,7 & 1,83 & 1,02 & 1,04 & 1,05 & 1,07 & 1,17 & 1,17 \\
Índices médios & 1,14 & 1,22 & 1,14 & 1,11 & 1,13 & 1,1 & 1,11 & 1,11 \\
\hline Painel B - Índice de Conservadorismo para o Lucro Líquido (ICLL) & & \\
\hline Instituição financeira & $\mathbf{2 0 1 0}$ & $\mathbf{2 0 1 1}$ & $\mathbf{2 0 1 2}$ & $\mathbf{2 0 1 3}$ & $\mathbf{2 0 1 4}$ & $\mathbf{2 0 1 5}$ & $\mathbf{2 0 1 6}$ & $\mathbf{2 0 1 7}$ \\
\hline Banco ABC S.A. & 1 & 1 & 1,06 & 1,01 & 1,06 & 1,05 & 0,96 & 1,02 \\
Banco Alfa de Investimento & 1,01 & 1 & 1,46 & 1,34 & 0,96 & 1,05 & 1,09 & 0,68 \\
Banco Daycoval S.A. & 0,91 & 0,96 & 1,01 & 0,99 & 0,97 & 1,1 & 1,02 & 1,04 \\
Banco do Brasil S.A. & 0,97 & 1,05 & 0,93 & 0,72 & 1,19 & 1,1 & 1,08 & 1,11 \\
Estado do Rio Grande do Sul S.A. & 1,03 & 1,03 & 1,02 & 0,95 & 0,9 & 1,04 & 1,1 & 1,04 \\
Banco Santander Brasil S.A. & 1,91 & 2,18 & 2,02 & 2,78 & 2,64 & 1,41 & 1,35 & 1,14 \\
Banco Itaú Unibanco Holding S.A. & 1,59 & 1,84 & 0,97 & 1,05 & 1,08 & 1,12 & 1,09 & 1,01 \\
Índices médios & 1,2 & 1,3 & 1,21 & 1,26 & 1,26 & 1,12 & 1,1 & 1,01 \\
\hline
\end{tabular}

Fonte: Elaborado pelos autores a partir dos dados da pesquisa.

O índice de conservadorismo maior que 1 na Tabela 8, aponta que patrimônio líquido e lucro líquido, é mais conservador pelas normas contábeis do BACEN que pelas normas IFRS. O que confirma os achados anteriores de Pelucio-Grecco, Geron e Macias (2019), de Santos e Calixto (2010) e de Brito, Lopes e Coelho (2012). Nota-se que na maior parte das empresas o lucro líquido apurado pelo BACEN é mais conservador que aquele apurado pelo IFRS. Sendo que, no ano de 2015 foi a realidade para todas os bancos da amostra. Ademais, o Bancos Santander apresentou maior conservadorismo pelo BACEN que pelo IFRS em todos os anos estudados. Foi possível também observar que, com relação ao patrimônio líquido, os números divulgados segundo o padrão do BACEN são mais conservadores que os números divulgados seguindo as normas internacionais das IFRS para todos os bancos e em todos os anos. Isso demostra que embora em algum ano específico o resultado apurado pelo IFRS pode ser mais conservador que o BACEN, de forma permanente o BACEN é sempre mais conservador.

Como já mencionado, as normas internacionais de contabilidade introduziram importantes conceitos do direito societário e trouxeram inovações tanto para as demonstrações contábeis quanto para as práticas contábeis, visto que essas normas são baseadas mais em princípios do que regras (ANTUNES et al., 2010). Consequentemente, as IFRS usam mais o julgamento, diferentemente das normas estabelecidas pelo Banco 
Central do Brasil, que definem critérios mínimos de reconhecimentos de ativos e passivos. Corroborando o exposto, os respondentes entendem que o BACEN, o que também é observado no teste do modelo adaptado do Índice de Conservadorismo proposto por Gray (1988).

\subsection{Análise qualitativa através das informações coletadas nas entrevistas}

Os efeitos práticos da adoção das IFRS pelos bancos levantados com os respondentes foram categorizados em três temas: (i) desenvolvimento e parametrização de sistemas de tecnologia; (ii) treinamento de pessoal; e (iii) custo de observância.

Na implantação de softwares usados na gestão empresarial, denominados sistemas ERP - Enterprise Resource Planning (Planejamento de Recursos Empresariais), há uma preocupação intensa com a tecnologia e quase nenhuma com os demais aspectos que norteiam as modificações nas dinâmicas organizacionais causadas por ela. Os dirigentes se esquecem de que as modificações causadas pela mudança tecnológica vão além de uma simples troca de sistema informacional e irão impactar também a estrutura e os aspectos sociocomportamentais (JESUS; OLIVEIRA, 2006).

A maioria dos especialistas comenta que esse efeito gerou os maiores impactos no processo de implantação das normas internacionais de contabilidade pelos bancos brasileiros. Podemos considerar que a mudança sistêmica aconteceu em dois momentos. $\mathrm{O}$ primeiro foi a implantação das normas internacionais em 2010, primeiro ano obrigatório da adoção. Nessa data, houve dificuldade por parte dos bancos em duplicar a plataforma contábil e criar processos dentro dos sistemas operacionais para gerar as informações nos dois padrões contábeis. Esse desenvolvimento gerou muitas horas de trabalho tanto dos especialistas contábeis, para especificar as novas regras de cada produto e adequar, por exemplo, as diferenças de classificação de instrumentos financeiros e taxas efetivas dos contratos, entre outros efeitos, quanto dos profissionais da área de tecnologia para implantar tais processos.

O segundo momento refere-se à implantação das IFRS 9. Os bancos tiveram grande dificuldade em identificar os sistemas adequados que realizassem a correta alocação dos modelos de negócios, o teste para avaliar se os ativos financeiros se enquadram nos critérios de pagamento exclusivo do principal e dos juros, conhecido pela sigla SPPI (Solely payments of principal and interest), e principalmente o cálculo de perda esperada para os ativos financeiros. Os bancos de maior porte avaliaram diversos motores de cálculo, tais como SAS IFRS 9, SAP Bank Analyzer, GDS Modellica, porém a grande maioria dos bancos brasileiros prepara seus registros contábeis de acordo com o BACEN e faz ajustes de conversão para as IFRS. Tais ferramentas internacionais não estavam prontas para uma implementação rápida para migrar as contas do COSIF, gerando ajustes de customização. Bancos menores realizaram adaptações em seus sistemas legados, fazendo uso de Access e Excel para se adequar à nova norma.

Acerca do treinamento de pessoal, é esperado que toda mudança em processos internos de uma organização gera a necessidade de treinamento do pessoal envolvido. Os profissionais da área contábil e das auditorias interna e externa tiveram de estudar as normas que estavam sendo implantadas, de forma que os efeitos das diferenças entre os dois critérios contábeis fossem mensurados com segurança. 
Para esse item, a maior dificuldade foi conseguir o envolvimento de outras áreas relacionadas à área contábil e à controladoria, como as áreas operacionais (back-office) e de gestão de riscos, bem como as áreas de negócio, como a área de tesouraria. Esses profissionais, por não terem seus resultados medidos nas IFRS, criaram barreiras no sentido de não se envolverem com o processo de implantação das normas nas IFRS. O grande motivo para essa resistência é que essas alterações eram apenas contábeis e não de negócio, uma vez que os efeitos dos resultados não seriam medidos para fins de pagamento de dividendos ou ainda dos tributos sobre o lucro.

Como já mencionado, o BACEN, ao emitir a Resolução 3.786 em 2010, obriga os bancos a preparar e emitir suas demonstrações financeiras de acordo com as regras estabelecidas por esse regulador, bem como de acordo com as normas internacionais de contabilidade, as IFRS (BACEN, 2009).

Com isso, houve incremento em custos relacionados a treinamento de pessoal, para entendimento das novas normas e adequação dos sistemas operacionais, de forma que pudessem atender à contabilização dos efeitos das diferenças de práticas contábeis, em custos com horas do pessoal interno para preparação dessas demonstrações nas IFRS, bem como em custos com a auditoria externa para revisão e emissão de parecer das mesmas.

Além disso, a Receita Federal também não acatou todas as novas IFRS para a apuração do lucro tributável. Todos esses itens mencionados nos parágrafos acima geram um incremento de custos de observância para as instituições financeiras que encarece o sistema financeiro nacional.

\subsection{Utilidade da emissão e da divulgação das demonstrações financeiras nas IFRS pelos bancos brasileiros}

A utilidade da demonstração financeira depende do motivo pelo qual a mesma é emitida pois a utilidade da demonstração financeira divulgada segundo as normas internacionais varia conforme cada tipo de instituição financeira. De acordo com a relação de instituições em funcionamento do país disponível no site do BACEN, a relação de classes de controle se resume em: i) privado nacional com controle nacional; ii) privado nacional com controle estrangeiro; iii) privado nacional com participação estrangeira; iv) estrangeiro com participação estrangeira; v) público estadual; e vi) público federal.

Para as instituições financeiras que possuem como controladoras empresas holdings de capital aberto, trimestralmente são preparados números em IFRS (sem a emissão de demonstrativos ao mercado) para que suas holdings possam efetuar o processo de consolidação e de divulgação no mesmo padrão contábil.

No caso de instituições financeiras com controle estrangeiro, as demonstrações financeiras em IFRS são utilizadas para medir o desempenho, ou seja, para o pagamento de bônus e participação nos lucros e resultados, bem como para a controladora medir o bom andamento da subsidiária brasileira.

Por outro lado, a respondente de um banco estrangeiro, porém com matriz nos Estados Unidos, comentou que a demonstração financeira nas IFRS é utilizada apenas para a divulgação no site do próprio banco para o atendimento dos requerimentos do BACEN. Não há nenhuma outra utilização dessa demonstração. 
O mesmo comentário foi feito por um respondente profissional de um banco privado com controle nacional. Ele mencionou que as demonstrações financeiras nas IFRS não são utilizadas para outro fim senão a divulgação no próprio site da instituição. No caso de instituição financeira com controle exclusivamente nacional, a análise do desempenho e o pagamento de dividendos, a participação nos lucros e os resultados e bônus da administração são pagos com base nos resultados gerados conforme os padrões estabelecidos pelo BACEN.

\section{Considerações Finais}

Considerando que o processo de convergências às IFRS para os bancos brasileiros não foi realizado em sua totalidade, a proposta de desenvolvimento desta pesquisa teve como objetivo verificar, através dos pontos de vista qualitativo, por meio das entrevistas efetuadas utilizando o método Delphi, e quantitativo, através dos números analisados disponíveis nas demonstrações financeiras dos bancos que foram selecionados na amostra, os efeitos da adoção parcial e compulsória pelos bancos brasileiros das normas internacionais de contabilidade em seus resultados e na percepção dos gestores e profissionais da área contábil destas instituições, bem como auditores externos e analistas do mercado financeiros.

O resultado sobre as consequências práticas do processo de implantação das IFRS no setor bancário relaciona questões com ambiente de TI, em que os sistemas tiveram de ser customizados para atender aos requisitos dos dois conjuntos de normas contábeis, gerando um acréscimo do custo com os sistemas operacionais e as horas dos profissionais envolvidos na parametrização dos processos e na especificação dos relatórios. Outra questão está relacionada com as pessoas. Os profissionais envolvidos em todo o processo contábil, seja o próprio departamento de contabilidade, assim como aqueles departamentos que geram informações que são capturadas nas demonstrações financeiras, tiveram de receber treinamento para que as diferenças entre as práticas contábeis fossem mensuradas e corretamente implantadas.

Para a questão sobre a utilidade da demonstração financeira nas IFRS, os resultados apontam que a utilidade varia de acordo com a classe de controle das instituições brasileiras.

As instituições em que o controle é privado nacional com controle nacional por empresa do setor financeiro, as demonstrações financeiras nas IFRS são elaboradas para cumprir os requisitos da norma do órgão regulador, não tendo outra finalidade, uma vez que a base de cálculo dos impostos e dividendos são os números no padrão contábil local. Por outro lado, instituições que são controladas por empresas de outro setor preparam os fechamentos contábeis nas IFRS e divulgam para suas controladas que as utilizam no processo de consolidação de seus números.

As demonstrações nas IFRS têm utilidade para aquelas instituições com controle estrangeiro, e nesse caso o desempenho contábil é medido com base nos números nas IFRS, envolvendo inclusive o pagamento de dividendos e bônus da administração.

A partir dos resultados da pesquisa realizada, pode-se concluir que a adoção das normas nas IFRS trouxe diversas consequências práticas para as instituições financeiras, com efeito tanto nas questões operacionais como no ambiente de TI, nos procedimentos de controle interno, no treinamento de pessoa e na utilidade das informações disponibilizadas. 
Com relação aos resultados apurados pelos bancos estudados, conclui-se que os resultados apurados à luz das normas do BACEN são mais conservadores que aqueles apurados à luz das IFRS, sendo que a diferença da rentabilidade do ativo apurada entre os dois modelos é significativa. O que demonstra que, no caso de o BACEN fazer uma adoção completa das IFRS haverá uma alteração significativa no lucro que é utilizado como base para cálculo de tributos e para distribuição de dividendos.

\section{REFERÊNCIAS}

ANTUNES, M. T. P.; SAIKI, T. G.; PELUCIO-GRECCO, M. C. Reconhecimento de Ativos Intangíveis em Situação de Business Combinations Face ao Alinhamento da Contabilidade Brasileira às IFRS. In: Anais do Congresso Brasileiro de Custos-ABC. 2010 .

ANTUNES, M. T. P.; PELUCIO-GRECCO, M. C.; FORMIGONI, H.; MENDONÇA NETO, O. R. A adoção no Brasil das normas internacionais de contabilidade IFRS: o processo e seus impactos na qualidade da informação contábil. Revista de Economia e Relações Internacionais, v. 10, n. 20, p. 5-19, 2012.

BACEN. Circular no. 1.273: Plano contábil das Instituições do Sistema Financeiro Nacional - COSIF. 1987. Recuperado de: https://www3.bcb.gov.br/aplica/cosif.

BACEN. Resolução n. 3.786 de 24 de setembro de 2009. Dispõe sobre a elaboração e a divulgação de demonstrações contábeis consolidadadas com a base no padrão contábil internacional emitido pelo international Accounting Standards Board (IASB). Recuperado de:

http://www.bcb.gov.br/pre/normativos/busca/downloadNormativo.asp?arquivo=/Lists/No rmativos/Attachments/47513/Res_3786_v1_O.pdf.

BALL, R., ROBIN, A., SHUANG WU, J. Incentives versus standards: properties of accounting income in four East Asian countries. Journal of Accounting and Economics 36 (2003) 235-270, 2003.

BASU, S. The conservatism principle and the asymmetric timeliness of earnings. Journal of Accounting and Economics 243 37, 1997.

BRITO, G. A. S.; LOPES, A. B.; COELHO, A. C. D. Conservadorismo nos lucros contábeis dos bancos no Brasil: a influência do controle estatal. Revista Universo Contábil, v. 8, n. 4, p. 19-39, 2012.

CHOI, F. D., FROST, C. A., MEEK, G. K. Accounting classification and the international harmonisation debate - an empirical investigation. Accounting, Organizations and Society, v. 26, p. 327-349, 2001.

DANTAS, J. A.; PAULO, E.; MEDEIROS, O. R. Conservadorismo condicional na indústria bancária brasileira em situações de maior percepção de risco. Revista Universo Contábil, v. 9, n. 2, p. 83-103, 2013.

DE FREITAS DANEBERG, T.; DECOURT, R. F. Impactos da adoção das International Financial Reporting Standards (IFRS) nos indicadores econômico-financeiros de 
instituições financeiras brasileiras. Revista Contemporânea de Contabilidade, v. 18, n. 46, p. 80-96, 2021.

DE LIMA, G. A. S. F.; DA FONSECA, J. A. S.; BRITO, G. A. S. Conservadorismo nos resultados contábeis dos bancos em Portugal. In: Congresso USP de Controladoria e Contabilidade, 9., 2009, São Paulo. Anais... São Paulo: FEA/USP, 2009. CD-ROM.

DUAN, Y.; NIU, J. Liquidity creation and bank profitability. The North American Journal of Economics and Finance, v. 54, p. 101250, 2020.

FARIAS, J.B.; PONTE, V.M.R.; OLIVEIRA, M.C.; DE LUCA, M.M.M. Impactos da adoção das IFRS nas demonstrações consolidadas dos bancos listados na BM\&FBOVESPA. Revista Universo Contábil, v. 10, n. 2, p. 63-83, 2014.

GERON, C. M. S. Evolução das práticas contábeis no Brasil nos últimos 30 anos: da Lei 6.404/76 à Lei 11.638/07. 2008. Dissertação (Mestrado em Controladoria e Contabilidade: Contabilidade) - Faculdade de Economia, Administração e Contabilidade, Universidade de São Paulo, São Paulo, 2008.

GIROTTO, M. Ambiente regulatório prudencial e a convergência de normas das instituições financeiras. Revista Brasileira de Contabilidade, n. 202, p. 6-13, 2013.

GRAY, S. J. Towards a theory of cultural influence on the development of accounting systems internationally. Abacus, v. 24, n. 1, p. 1-15, 1988.

GRECCO, G. B.; PELUCIO-GRECCO, M. C.; ANTUNES, M. T. P. Risco Fiscal sob Responsabilidade das Organizações Contábeis Brasileiras: Uma Proposta para Mitigação. Tecnologias de Administração e Contabilidade, v. 6, p. 76-94, 2016.

PELUCIO-GRECCO, M. C. P.; GERON, C. M. S.; FORMIGONI, H. O impacto das mudanças nas práticas contábeis no nível de conservadorismo das companhias abertas brasileiras. In: Anais do Congresso Brasileiro de Custos-ABC. 2009.

JEANJEAN, T., STOLOWY H. Do accounting standards matter? An exploratory analysis of earnings management before and after IFRS adoption. Journal of Accounting and Public Policy. Volume 27, Issue 6, November-December 2008, Pages 480-494, 2008.

JESUS, R. G.; DE OLIVEIRA, M. O. F. Implantação de sistemas ERP: tecnologia e pessoas na implantação do SAP R/3. JISTEM: Journal of Information Systems and Technology Management, v. 3, n. 3, p. 315-329, 2006.

MACEDO, M. A. S., MACHADO, M. A. V., MURCIA, F. D., MACHADO, M. R. Análise do impacto da substituição do DOAR pela DFC: um estudo sob a perspectiva do value relevance. Revista de Contabilidade de Finanças, FEA USP, São Paulo, 2010.

MARTINS, E. A contabilidade brasileira de ontem e de hoje; e a de depois?. Contabilidade e finanças no Brasil: estudo em homenagem ao professor Eliseu Martins, 2012. São Paulo: Atlas. 
MARTINS, V. G., DE OLIVEIRA, A.S.; NIYAMA, J.K.; DINIZ, J.A. Níveis diferenciados de governança e a qualidade da informação contábil no processo de convergência às normas internacionais. Contexto, v. 14, n. 27, p. 23-42, 2014.

MARTINS, E.; GELBCKE, E. R.; SANTOS, A.; IUDÍCIBUS, S. Manual de Contabilidade Societária: aplicável à todas as sociedades: de acordo com as normas internacionais e do CPC. $2^{\mathrm{a}}$ Edição. São Paulo: Ed. Atlas, 2013.

PADOVEZE, C. L., BENEDICTO, G.C. DE, LEITE, J. S. J. Manual de Contabilidade Internacional: IFRS: USGAAP e BR GAAP: Teoria e Prática. 1.ed. São Paulo: Cengage Learning, 2012.

PAUlO, E., ANTUNES, M T. P., FORMIGONI, H. Conservadorismo contábil nas companhias abertas e fechadas brasileiras. ERA - Revista de Administração de Empresas, v.48, n.3, p. 46-60, 2008.

PELUCIO-GRECCO, M. C.; GERON, C. M. S.; MACIAS-CARDONA, H. A. IFRS adoption and company conservatism in Colombia and Brazil Adoção das IFRS e conservadorismo das companhias na Colômbia e no Brasil.

PESSANHA, G. R. G.; CALEGARIO, C. L. L., SAFADI, T., \& DE AZARA, L. N. Impactos das estratégias de fusão e aquisição na rentabilidade dos bancos adquirentes: uma aplicação dos modelos de intervenção no setor bancário brasileiro. RAM. Revista de Administração Mackenzie, v. 13, n. 5, p. 101-134, 2012.

QUEIROZ, J. M.; RODRIGUES, A.; DA SILVA MACEDO, M.A.; SZUSTER, N. Análise dos efeitos dos instrumentos financeiros no conservadorismo contábil em bancos brasileiros. Revista Contemporânea de Contabilidade, v. 17, n. 44, p. 3-16, 2020.

SANTOS, E. S.; CALIXTO, L. Impactos do início da harmonização contábil internacional (Lei 11.638/07) em resultados d'empresas abertas. RAE eletrônica, v. 9, n. 1, p. 0-0, 2010.

SANTOS, L. P.G., LIMA, G. A. S. F DE, FREITAS, S. C., LIMA, I. S. Efeito da Lei 11.638/07 sobre o conservadorismo condicional das empresas listadas BM\&FBOVESPA. R. Cont. Fin. - USP, São Paulo, v. 22, n. 56, p. 174-188, maio/jun./jul./ago, 2011.

SILVA, R. L. M. Adoção completa das IFRS no Brasil: qualidade das demonstrações contábeis e o custo de capital próprio. Tese (Doutorado em Controladoria e Contabilidade: Contabilidade) - Universidade de São Paulo, São Paulo, 2013.

TAVARES, M. F. N.; DOS ANJOS, L. C. M.; PAULO, E. Contribuições enviadas ao IASB/FASB referentes à revisão do draft de reconhecimento de receitas. ContextusRevista Contemporânea de Economia e Gestão, v. 12, n. 3, p. 35-63, 2014.

VAN TENDELOO, B., VANSTRAELEN, A. Earnings management under German GAAP versus IFRS. The European Accounting Review, 14(1), 155-180, 2005.

TRIVIÑOS, A. N. S. Introdução à pesquisa em ciências sociais: a pesquisa qualitativa em educação. São Paulo: Atlas, 1987.

WATTS, R. L. Conservatism in Accounting Part I. explanations and implications. Accounting Horizon, v.17, n.3, p. 207 - 221. 2003. 


\section{RMP}

WEETMAN, P., JONES, E. A. E., ADAMS, C. A., GRAY, S. J. Profit Measurement and UK Accounting Standards: A Case of Increasing Disharmony in Relation to US GAAP and IASs. Accounting and Business Research, v. 28, n. 3, p. 189-208, 1998. Recuperado de: https://www.tandfonline.com/doi/abs/10.1080/00014788.1998.9728909 